\title{
EVOLUTION OF THE LABOUR MARKET IN THE ROMANIAN ECONOMY
}

\author{
Ionela Gavrilă-Paven ${ }^{1}$ \\ Dumitru Ciucur ${ }^{2}$
}

\begin{abstract}
Labour productivity is a concept and a parameter that continues to be in centre of everyone's attention all over the world, due to its impact upon the all states' economy. It is the subject of many specialists' discussions and prediction for the near or long term future and also the relations that are affecting directly or indirectly the evolution of the economic progress. Specialists from each country are analyzing the crisis' effects upon the employees' number and their salary level and are trying to find solutions for surpassing the crisis from their country. Romanian economy only in 2009 could really quantify the first effects of the financial crisis upon the employees' number.
\end{abstract}

Key words: labour market, productivity level, prices consumption index, monthly medium salary

JEL codes: D24, J24, J31, O31.

\section{Introduction}

Human beings were endowed by Mother Nature with numerous characteristics that can create economic value. Our arms, legs and backs can perform physical labour. Our hands and fingers can mild and manipulate objects. Our brains can reason, imagine and innovate. Our human spirit can entertain, comfort and inspire.

In its primitive level of economic development, work involved sheer muscle powerdigging, lifting, hauling and the like. Our forebears hunted, gathered and carved furrows for crops eventually harvested by hand. Armies of workers, hauling huge stones with only simple tools, built Egypt's pyramids. Some workers earned their living exploiting other talents, but muscle power dominated economic life until the Industrial Revolution.

The new age brought machines stronger and more durable than muscle power, and they took on more of the physical work. People's niche became manual dexterity, the ability to control tools with motor skills. Human hands were needed to operate machinery. We worked with power drills and forklifts rather than picks and shovels.

New technology led to automation sophisticated enough to run the machines, reducing the number of workers on the factory floor. Many modern factories employ just a few highly trained technicians to maintain the computers that run nearly all phases of production.

\section{Literature review}

Labour productivity is a concept and a parameter that continues to be in centre of everyone's attention all over the world, due to its impact upon the all states' economy. It is the subject of many specialists' discussions and prediction for the near or long term future and also the relations that are affecting directly or indirectly the evolution of the economic progress. Specialists from each country are analyzing the crisis' effects upon the employees' number and their salary level and are trying to find solutions for surpassing the crisis from their country. Romanian economy only in 2009 could really quantify the first effects of the financial crisis upon the employees' number.

\footnotetext{
1 “1 Decembrie 1918” University of Alba Iulia, str. N. Iorga, Nr. 11-13, Romania, ionelapaven@ yahoo.com

${ }^{2}$ Economic Studies Academy, Bucharest, str. Caderea Bastiliei, Nr. 1, Romania
} 
Specialists made only predictions until now regarding the Romanian economy and only now can be observed the real effects of the crisis. There are studies regarding the labour productivity and its evolution all over the world and its impact upon the economic and social progress.

One of the most important aspects of the labour productivity that has to be considered is that the human work in many fields can be replaced with machines, robots and other aggregates. In this way the productivity for a company increases. So, in these conditions human resources have to be able adapt and to learn for their entire active life, so that they will be able to fill in the new positions that can appear on the working market. In other words they have to learn for their entire life, respectively the concept long life learning.

\section{Research methodology}

Monthly data regarding the medium real and net salary and the number of employees are obtained from a selective statistical research. Starting with January 2009, the data that were used ware collected considering the new Classification of the national economy's activities, classification that was harmonized with the European classification. In this data gathering was used information from 24000 economic and social entities. Entities from the budgetary sector (public administration, education, health and social assistance) are exhaustive included in research. From the economic sector were included in research entities with at least 4 employees, that covers almost 99, 69\% of the employees. The total amount of the employees from the excluded economic entities, those that have less than 3 employees, represent approximately 7, 92\% from the total number of employees in the economic sector.

\section{Evolution of the labour market in the Romanian economy}

Nature endowed human beings with numerous characteristics that can create economic value. Our arms, legs and backs can perform physical labour. Our hands and fingers can mild and manipulate objects. Our brains can reason, imagine and innovate. Our human spirit can entertain, comfort and inspire.

As productivity reorganizes the economy, it changes how we use our innate skills and talents in the workplace. The progression flows mainly from technology and trade. Each generation of inventions and innovations produces tools to take on more of the tasks once done by human beings. Each expansion of trade opens the possibility of doing tasks more economically in countries paying lower wages.

At the most primitive level of economic development, work involved sheer muscle powerdigging, lifting, hauling and the like. Our forebears hunted, gathered and carved furrows for crops eventually harvested by hand. Armies of workers, hauling huge stones with only simple tools, built Egypt's pyramids. Some workers earned their living exploiting other talents, but muscle power dominated economic life until the Industrial Revolution.

The new age brought machines stronger and more durable than muscle power, and they took on more of the physical work. People's niche became manual dexterity, the ability to control tools with motor skills. Human hands were needed to operate machinery. We worked with power drills and forklifts rather than picks and shovels.

New technology led to automation sophisticated enough to run the machines, reducing the number of workers on the factory floor. Many modern factories employ just a few highly trained technicians to maintain the computers that run nearly all phases of production.

People who once operated machinery found work that relied more on using their minds. At first, many jobs called for formulaic intelligence, applying rote standards in keeping ledgers, counting and other duties. The next step upward involves jobs that required analytical reasoning and the ability to solve problems. We took jobs as engineers, managers and programmers.

In our time, computers are taking on many of the mental tasks that not long ago only humans could do. At first, the machines could handle only the relatively simple tasks of formulaic 
intelligence, proving faster and more accurate in calculating than the human brain. Increasingly powerful computers, capable of running huge programs, now perform more of our analytical tasks. Advances in artificial intelligence enable computers to fly planes, answer phone calls and track buying patterns. An IBM computer even beat world chess champion Garry Kasparov in 1997.

In today's world, companies and workers face the challenge of ascending the hierarchy of human talents. Workers are increasingly using those traits that make us truly human. Some jobs require imagination and creativity, including the ability to design, innovates and entertains. Other jobs rely on such social skills as conflict resolution, cooperation and even humour. Work is more likely to put a premium on the ability to inspire and motivate, a capacity social scientists call emotional intelligence.

Many jobs requiring muscle power, manual dexterity and formulaic intelligence are increasingly performed by workers in other countries. As the Internet speeds communications, companies are hiring more foreigners with analytical skills.

Regarding the Romanian labour market we have to point out its evolution after 1989, and we will concentrate upon the data from the last period, since 2007 and until 2009.

In the first years of transition, Romania has faced an unemployment boom, on the basis of the structural changes in the national economy. By the process of restructuration, privatization, closeout of the companies having mainly a state capital, the structure of the employment force has changed, i.e. employment in the state sector was reduced as a result of the processes of restructuration, privatization and closeout, while employment in the private sector has increased.

As a result of the imbalances caused by passing to market economy, the massive personal dismissals induced by the process of restructuration or closeout of the economical unit led to the decreasing of the number of employees and to increase of number of unemployed. It is necessary that the social policy should start from the need for a radical change in approaching this subject. To create minimum conditions for citizens to be able to actually take part in the social life it is necessary that the legislative guarantees should be ensured urgently in parallel with continuous increase of the individual responsibility level.

The social model for achieving this must rely on the equilibrium between competition, cooperation and solidarity, by differential pay according to efficiency criteria and by balanced and transparent distributions of incomes earned in the society. In order to come out from the economic crisis in which lies, Romania needs more work places on the basis of the social solidarity.

The main objective is to ensure the protection and social welfare measures for certain categories or groups of persons able to work, by actions which will contribute to securing the work place, to attain permanent and rising incomes, as an essential premise for improving the living conditions of the active persons in the labor market.

Though the economy did a good progress after 2000, best to be seen at the GDP of Romania the current question is if this growth is sustainable after 2009 or not - especially when facing a worldwide crisis. But the future prospects for the economy do not depend only on external factors. The internal political and economical frame counts as well.

So let's have a look on the driving forces for the progresses in the last years. At first, an important part of growth in Romania was more a catch-up effect: if starting from a low level, even small achievements appear like big steps after they have been transformed into percentages. In absolute terms the GDP of Romania keeps being on a very low level, though it is certainly not idle and reached even more than a good third of the European average.

Main issues are extremely large regional disparities in Romania as they don't improve at all. Thus, a real development is limited to some few economic centers in Romania, but other regions are more or less idle. This issue is quite an important one, as it leaves a lot of resources of the economy unused.

Regarding the evolution of the medium monthly salary we observe that for the August 2009 it was around 320 Euro, recording a slightly decreasing compared with July 2009, by 3\%. The 
highest level for the medium monthly salary ware recorded in the cocks industry and the petroleum industry (around 800 Euro) and the smaller in the manufactory industry (around 190 Euro).

Comparing the evolution of the monthly salary with the consumption index evolution, we can see that it decreased for August 2009 compared to July 2009, representing in August only $97,2 \%$ and being calculated as a fraction between monthly medium salary and consumption prices index. Compared to October 1990, the monthly medium salary index was of $122,7 \%$ with 3,6\% smaller than the one registered in July 2009.

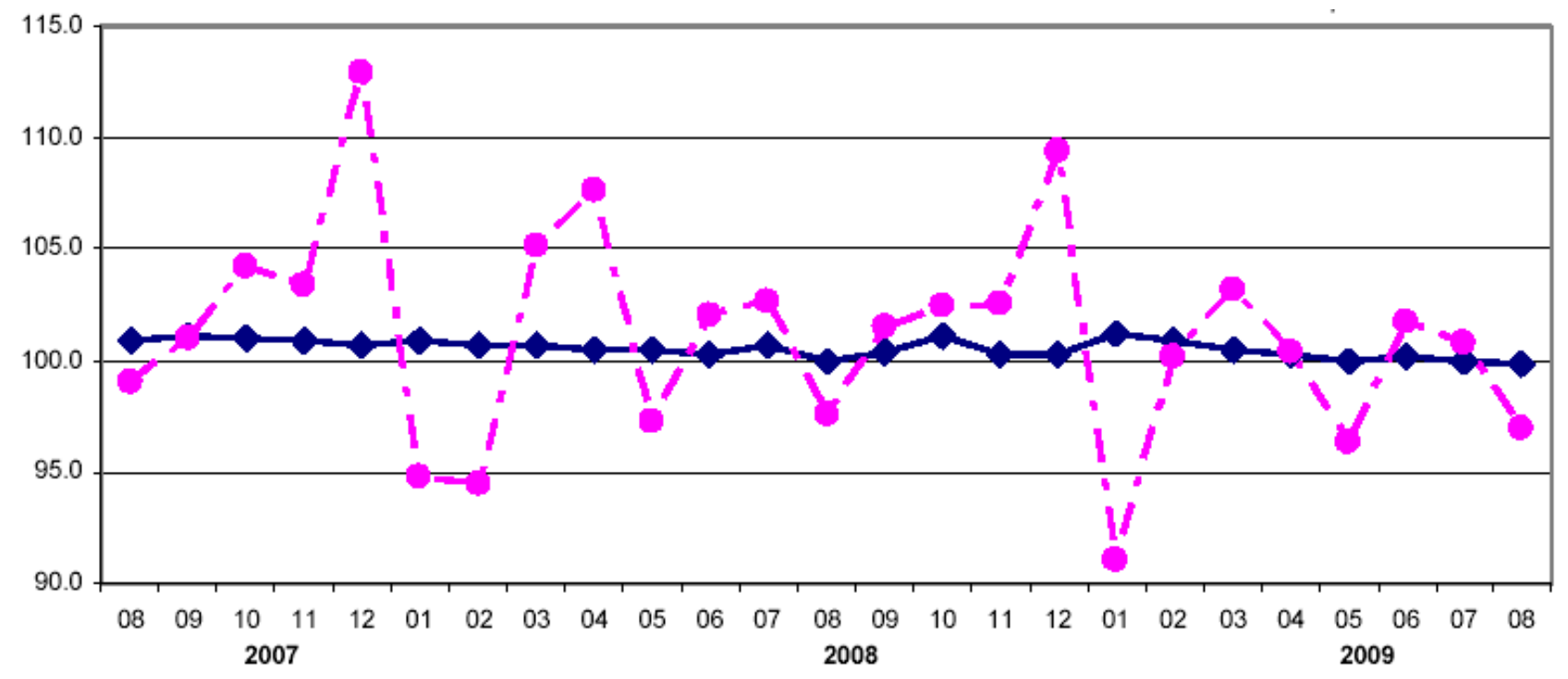

Fig. no. 1 - Evolution of the monthly medium salary index and consumption prices index between August 2007 and August 2009

During the 2009 there are recorded fluctuations of the monthly medium salary determined mainly by the approval of the $13^{\text {th }}$ salary and the holidays' bonus (in December, March/April). These bonuses influences the increasing and decreasing of the monthly medium salary depending on the period in which they are approved, leading, finally to the fluctuation of the salary's index compared to the consumption prices' index as it is shown in figure number 1.

In August 2009 compared to July 2009 for the majority of the economic activities the monthly medium salary was decreasing, the main causes being: the restriction of the activities' dimensions, the approvals in the last month of the benefits from the recorded profit and bonuses for the activities during the first semester of the year (including also holidays' bonuses).

Diminishing in the monthly medium salary was recorded as it follows:

o between $7 \%$ and $10 \%$ in automobile industry for small vehicles, trailers and small trailers, public administration, pharmaceutical products and pharmaceutical preparations' industry;

$\circ$ between $5 \%$ and $7 \%$ in the textile manufactory industry, petroleum extraction and natural gases industry, chemical substances and products industry, education, vehicles manufactory, other equipments and machines, other manufactory transportation vehicles, metallic constructions and metallic products' industry, representing the machines, equipments and installations;

$\circ$ and between $4 \%$ and $5 \%$ in textile manufactory industry, leather goods' industry, collecting, treating and distribution of water, other activities and services.

Increasing in the monthly medium salary in August 2009 compared to July 2009 were determined by the occasionally bonuses (performances bonuses, holidays' bonuses), products' bonuses and cash prizes from the salary fund and the overproductions accomplishments as it follows: 

manufacturing;

o by $14 \%$ in making cocks products and the products obtained from petroleum

○ between $3 \%$ and 5\% in metallurgical industry, editing activities, metal mining extractions, drinking manufactory.

In August 2009 compared with August 2008 the monthly medium salary increased by 5,6\%, and compared with the same period of last year the monthly medium real salary recorded an increase by $5,6 \%$.

One of the biggest problems that are appearing in the last period of time are referring to the aging process of the population and the measures that are taken in this sector.

European Union's suggestions regard also measures that have to be taken in the social protection area regarding the ageing phenomenon. Nevertheless, they included in their strategies, programmes or activity some measures regarding the ageing workforce.

Thus, we can mention here the government which stipulates in its Programme in Chapter 7 The Social Protection Policy that one of the active measure in this field will be the "Promotion of some special programmes in partnership in order to diminish long term unemployment affecting youngsters and persons over 45 years as well as persons that are facing integration difficulties".

The government policy is implemented by the ministries in the field, such as:

- The Ministry of Labour, Social Solidarity and Family (MoLSSF) (and its field offices (offices for labour, social solidarity and family)) is the specialised authority of the central public administration, subordinated to the Romanian government and has a comprehensive role to ensure and coordinate the implementation of governmental policies in the fields of labour, social solidarity, social protection and family.

$0 \quad$ One of the main objectives of the MLSSF is the drawing up of the legislation regarding workforce, including the ageing workforce. There are no specific legislative initiatives or drafts concerning old and/or ageing workforce, the already existing laws having a nondiscriminatory character, covering all age groups segments.

\section{Conclusions}

Though a breakdown of GDP into its expenditure components is currently unavailable, we highlight a number of leading indicators which point towards a continued deterioration in economic conditions. First, given that the Romanian consumer provides the backbone for the economy, contributing around $80 \%$ to the national output, the latest retail sales data provide an important indicator for the health of the wider economy. In this regard, the $17.3 \% \mathrm{y}$-o-y plunge in retail sales in June, which eclipsed the $12.3 \%$ fall in May and marks the fast rate of decline since the beginning of the NSI's data series in 2005, certainly does not bode well for the health of the wider economy. That the downturn in retail sales has yet to find a bottom suggests that economic growth in the third quarter could prove at least as bad as in the second.

The latest labour market data further suggest that consumer demand is set to remain weak for some time to come. The unemployment rate has continued to tread higher during the first half of the year, reaching $6.0 \%$ in June, while real wage growth has slowed to $2.4 \% \mathrm{y}-\mathrm{o}-\mathrm{y}$ in the same month from a 2009 peak of $12.9 \%$ in February. Given that unemployment is typically a lagging indicator of the business cycle, and is expected to continue swelling even after the economy shows signs of recovery, consumer demand will resultantly remain subdued through the remainder of 2009 and into 2010. 


\section{References}

1. Cindrea I., 2006. The Crisis on the Labor Market in Romania, „Lucian Blaga” University Sibiu.

2. Cordos M., 2007. Labour force migration impact in the European space upon the business firm in Romania, Lecturer, The International Scientific Conference - European Integration New Challenges for the Romanian Economy, Oradea, Romania.

3. Vasile V., 2004. Demographic Changes and Labour Market in Romania.

4. Miron D., Drăgan G., Păun L., Ilie F, Cibian M., Economia integrării europene, Ed. ASE, Bucureşti, 2002.

5. Conference des representants des gouvernements des Etats membres - Union Economique et Monetaire, Bruxelles, le 1 fevrier, 1992. Traite sur l'Union europeenne, CONF-UP-EUM, 2002/92.

6. Cox W. M., Alm R. A better way: productivity and reorganization in the American economy, http://www.dallasfed.org/fed/annual/2003/ar03.htm

7. http://ec.europa.eu/citizenship/eyv2011/doc/National\%20report\%20RO.pdf

8. http://www.emergingeuropemonitor.com/file/80872/economic-stabilisation-in-h209-expecta-weak-recovery 